IZA DP No. 8194

Coresidency, Ethnicity, and Happiness of China's Rural Elders

Rachel Connelly

Michael lannotti

Margaret Maurer-Fazio

Dandan Zhang

May 2014 


\title{
Coresidency, Ethnicity, and Happiness of China's Rural Elders
}

\author{
Rachel Connelly
}

Bowdoin College and IZA

\author{
Michael lannotti \\ Bates College
}

\author{
Margaret Maurer-Fazio \\ Bates College and IZA \\ Dandan Zhang \\ Peking University
}
Discussion Paper No. 8194
May 2014

IZA

P.O. Box 7240

53072 Bonn

Germany

\author{
Phone: +49-228-3894-0 \\ Fax: +49-228-3894-180 \\ E-mail: iza@iza.org
}

\begin{abstract}
Any opinions expressed here are those of the author(s) and not those of IZA. Research published in this series may include views on policy, but the institute itself takes no institutional policy positions. The IZA research network is committed to the IZA Guiding Principles of Research Integrity.

The Institute for the Study of Labor (IZA) in Bonn is a local and virtual international research center and a place of communication between science, politics and business. IZA is an independent nonprofit organization supported by Deutsche Post Foundation. The center is associated with the University of Bonn and offers a stimulating research environment through its international network, workshops and conferences, data service, project support, research visits and doctoral program. IZA engages in (i) original and internationally competitive research in all fields of labor economics, (ii) development of policy concepts, and (iii) dissemination of research results and concepts to the interested public.
\end{abstract}

IZA Discussion Papers often represent preliminary work and are circulated to encourage discussion. Citation of such a paper should account for its provisional character. A revised version may be available directly from the author. 


\section{ABSTRACT}

\section{Coresidency, Ethnicity, and Happiness of China's Rural Elders}

As China moves into the ranks of aged societies, coresidency of elders with their adult children has become an increasingly important policy concern. This article utilizes data from the 2000 Population Census of China and the 2011 Chinese Household Ethnicity Survey (CHES) to analyze coresidency patterns of rural elders in seven Chinese provinces with high concentrations of ethnic minority populations. We also explore one consequence of coresidency, reported happiness. We find that socioeconomic variables matter in the determination of coresidency in China in ways that are very similar to their roles in other countries. However, changes between 2000 and 2011 in the effects of age and widowhood show that coresidency decisions among rural elders provinces are transitioning from childcentric to parent-centric. Our analysis also reveals the large role cultural norms play in determining coresidency, as evidenced by differences across ethnic groups. The CHES data allow us to compare coresidency across ethnicity with respect to both individual and regional degrees of assimilation versus isolation. Elders who do not speak Mandarin have higher rates of coresidency than those who do. Additionally, those who live in counties with low rates of intermarriage and intergroup friendships are also more likely to coreside. In exploring the determinants of happiness, we find again that socioeconomic and demographic conditions matter, as does ethnicity. Controlling all else, coresidency increases the happiness of the elderly by about 28 percent. Moreover, the unobserved characteristics that drive coresidency are highly detrimental to the happiness of the elderly.

JEL Classification: D13, J12, J14, J15

Keywords: coresidency, happiness, ethnicity, Minzu, global life satisfaction, elders, living arrangements, China Household Ethnicity Survey, China

Corresponding author:

Margaret Maurer-Fazio

Bates College

276 Pettengill Hall

4 Andrews Road

Lewiston, Maine 04240

USA

E-mail: mmaurer@bates.edu 


\section{Introduction}

Prior to industrialization, it was common for parents and male offspring to reside in the same household for the duration of the formers' lifespan. Coresidency facilitated the natural transition of the male child from dependent, to agricultural laborer, to caretaker of his elderly parents. In China, coresidency has also been reinforced by both a long history of the patrilineal, patrilocal ideals of Confucianism and legal precedent in addition to these universal practical purposes. However these factors have varying influence across the cultures of China's ethnic groups and coresidency trends differ across these groups.

Decades of Communist rule, coupled with the forces of modernization, urbanization, and migration brought on by economic reform have moved Chinese society beyond its Confucian roots. As a result, the share of rural Chinese adults over age 50 living with their adult children decreased from 73 to 60 percent between 1982 and 2000. ${ }^{1}$ Thus, while living with one’s children was clearly not universally practiced even in the early reform period, the share of elders living with their children declined substantially over this 18-year period. Although this decline of coresidency is consistent with historical global patterns, it appears to be detrimental to the subjective well-being of China's elderly.

The causes for the decline in coresidency are the subject of much recent interest. Motivation for such inquiry is driven by the rapid aging of the Chinese population and the nation's continued reliance on familial piety to provide the vast majority of old age support. The shift in living arrangements has been variously attributed to the erosion of Confucian principles of familial piety and its requirements and to practical factors, such as the proliferation of household laboursaving appliances, the expansion of the housing market, and increasing incomes. ${ }^{2}$ No doubt, the decline in coresidency is the result of a complex amalgam of forces that is beyond any single explanation.

In this article we utilize data from the 2011 Chinese Household Ethnicity Survey (CHES) to observe and analyze the coresidency patterns of rural elders in seven Chinese provinces with high concentrations of ethnic minority populations. ${ }^{3}$ After taking socioeconomic and demographic factors into account, we focus on the role that culture and ethnicity play in determining elders' living arrangements. Poston and Shu argue that China's minority ethnic groups display remarkable consistency in their distinctiveness from the Han. ${ }^{4}$ That is, ethnic groups that are similar to the Han are similar in many respects and those that differ, differ in many respects. We exploit cultural differences across ethnic groups, in conjunction with their typical living arraignments to explore the forces that drive coresidency.

\footnotetext{
${ }^{1}$ Author's calculations, based on micro samples of the 1982 and 2000 Population Censuses of China. Throughout the paper we define elders as those 50 years of age or older.

${ }^{2}$ Meng and Luo, 2008; Chu, Xie and Yu, 2011; Lei et al, 2011; Zhang, 2004; Zhan and Montgomery, 2003; Li and Chen, 2010; Chen, 2009, Zeng and Wang, 2003.

${ }^{3}$ Hunan, Guangxi, Guizhou, Ningxia, Qinghai, Xinjiang, and Inner Mongolia. Throughout the rest of the paper we refer to this group of provinces as Western provinces, despite Hunan's inclusion in the group.

${ }^{4}$ Poston and Shu 1987.
} 
The primary finding of our work is that the coresidency patterns of the elderly with their adult children do indeed vary by ethnic group even after taking socioeconomic factors into account. This suggests that, to a degree, coresidency is a function of cultural norms. Uyghurs and Tibetans demonstrate significantly higher rates of coresidency with their adult children than do the Han. The distinctiveness of the living arrangements of these two groups is additionally clear when the effects of widowhood are considered. Among other ethnic groups, particularly for women, losing a spouse greatly increases the likelihood of living with adult children; however the Uyghurs and Tibetans coreside at high rates even before widowhood.

At the same time, we find that the effects of demographic and socioeconomic determinants are consistent across ethnic groups. Coresidency increases as the elderly age past 70 and grow frail. Higher income decreases coresidency. Further testing the hypothesis of Poston and Shu, ${ }^{5}$ we examine variables that represent levels of cultural assimilation and integration at both individual and county levels, and find the probability of coresidency of the elderly increases with the degree of cultural isolation.

We begin our analysis by comparing the coresidency patterns of rural elders in 2000 to those in 2011. To do this, we employ data from the 1 percent sample of the 2000 Population Census of China, restricted to the same counties as included in the CHES data. Substantial change is evident in the patterns of coresidency by age and ethnicity. Borrowing terminology from Zhang, it appears that coresidency has become more parent-centric and less child-centric. ${ }^{6}$ Widowhood and age have larger effects on coresidency with adult children in 2011 than they did in 2000. The effects of ethnicity have also changed. The Han's rate of coresidency declined faster than most of the other included ethnic groups.

Next, based solely on the 2011 CHES data, we expand our analysis to include a more expansive set of socioeconomic and demographic variables and measures of individual and community attitudes and behavior regarding ethnic relations. Our analysis, privileged by the depth of the CHES data, both confirms the previous findings and demonstrates that coresidency is a function of elderly individuals' cultural assimilation to the majority Han.

Finally, focusing on a potential consequence of coresidency, we examine how the overall subjective happiness of the elderly differs by ethnicity and coresidency status. We find that coresidency with adult children increases elders' happiness; however the unobserved forces that drive the elderly to coreside, such as illness and low levels of income, negatively affect happiness.

\section{Comparison of Coresidency Patterns in CHES Counties, 2000 and 2011}

The 2011 CHES data is an ideal source for this work. It is richly detailed in comparison to the Census data, it privileges areas in China with large minority populations, and it is current.

\footnotetext{
${ }^{5}$ Poston and Shu 1987.

${ }^{6}$ Zhang, 2004.
} 
However, given its geographic focus on the West, it is not representative of all of China. In Table 1 we compare the share of rural elders (aged 50 and above) who live with their adult children across the 2000 Chinese Census and 2011 CHES data. Column 1 is based on the national-level census data. Column 2 is also based on census data, but restricted to elders dwelling in the CHES counties. Column 3 comes from the 2011 CHES data. We include all ethnic groups in our analysis for whom we have at least 40 female and 40 male elders. $^{7}$

\section{Tables 1 Here}

The first two columns in Table 1 provide information on differences in 2000 between rural elders in all Chinese provinces and the rural elders who reside in the CHES counties. For Han, Mongolian, Hui, Tibetan, and Tujia elders, those living in the CHES counties have substantially higher rates of coresidency with adult children than are typical of their own ethnicity in the national census sample. For the other minority groups listed in Table 1, the proportions living with their adult children are very similar between the full rural sample and the CHES sample. Only the Zhuang have slightly lower rates of coresidency in the CHES sample. That all but the Zhuang have equal or greater rates of coresidency in the CHES counties than nationally reveals that coresidency rates are high in rural Western China. This may be a function of the region's low income levels and/or its more traditional lifestyles.

Having established that CHES-county living arrangements are somewhat different from the national averages, we henceforth restrict our census sample to the CHES counties. Comparing the latter two columns of Table 1 allows us to explore changes in coresidency patterns over the decade of the 2000's. Over the entire population of the CHES counties, coresidency rates remained consistent, standing at 66.5 percent in 2000, and 65.0 percent in 2011 . However, by ethnic group these measures are less consistent. For the Han, coresidency declined 7 percentage points over the period. Two groups with very high rates of coresidency in 2000, the Mongolians and the Hui, exhibit a substantial decline from 2000 to 2011. Tibetans, on the other hand, who had the highest rates in 2000, had no change in coresidency over the period. Both Uyghurs and the Zhuang have higher rates of coresidency in 2011 than 2000.

Income has risen across the Western rural region in the 2000s, but it is reasonable to hypothesize that income increases could yield different effects for different groups; some may use extra income to build new houses nearby their parents, while other groups might use increased income to expand the size of multigenerational houses. ${ }^{8}$ Other factors may also be at play in the determination of differing patterns over time, such as differential rates of outmigration. Table 2 reveals the variation in average household size of rural elders of each

\footnotetext{
${ }^{7}$ Sample sizes by ethnic minority group can be calculated from sample means by ethnicity presented in Table 4 .

${ }^{8}$ Chen 2009.
} 
ethnic group while Table 3 reveals the share of elder households with at least one out-migrant at the time of the survey. Tibetans, Uyghurs and Salars have especially large average household size in 2011. Tibetans, Uyghurs and Mongolians have lower rates of outmigration than other ethnic groups.

Tables 2 and 3 Here

Table 4 compares the results of a probit regression model of the determinants of elders' coresidence with their adult children. It is based on a parsimonious specification that facilitates comparison between the 2000 Census data and the 2011 CHES data. We consider the effects of elders' education, age, gender, widowhood, provincial average rural per capita income and ethnicity on the likelihood of coresiding by regressing an indicator variable of elders' coresidence with adult children against a series of explanatory variables. Almost all of these variables are themselves binary variables, taking on a value of 1 to indicate a trait and a value of 0 to indicate its absence. For example, for elders with little or no formal schooling, the variable "less than primary school" is set to 1 and 0 otherwise. One category for each type of explanatory variable is omitted to serve as a reference group. Here we omit: male, attended middle school, age 50-54, not widowed, and Han ethnicity. In Tables 4 and 5 we report the marginal effects of the explanatory variables on coresidency. These marginal effects can be interpreted as percentage point differences. For example, in Table 4, column 1, we find that the marginal effect on elders' coresidency with their adult children of having an educational level of less than primary school is 0.026 . Since having attended middle school is the reference group, we interpret this marginal effect as indicating that elders with less than primary educations are, all else equal, 2.6 percentage points more likely to coreside with their children than those with middle school educations.

\section{Table 4 Here}

Table 4 shows that, in the 2000 Census sample, both low and high levels of educational attainment are important determinant of elders' coresidence with their adult children. Using the 2011 CHES data, we see once again that there is a significant and positive effect of low educational attainment on elders' likelihood of coresiding with their adult children. However, in 2011 this effect, while stronger at 6.4 percentage points, is present only for those who did not complete primary school. There is no significant difference in the probability of living with adult children between those who completed primary, middle, or high school.

There are interesting differences across the two samples in the effects of age on coresidency. We divide our samples into five-year age cohorts, using the 50-to-54 age category as the reference group. In 2000, all age cohorts between 60 and 74 are approximately 2 percentage points less likely to live with their adult children than those in the youngest two age cohorts. We expect that the younger elders live with their adult children because they are providing childcare 
for their grandchildren and other services to the prime-age adults in the household. The cohort of elders age 75 and older exhibit a rate of coresidency akin to the youngest groups, consistent with the supposition that these elders are in need of the physical and psychological support coresidency provides. This effect is drastically amplified in the 2011 sample, and moreover also pertains to the age 70-74 cohort. Additionally, by 2011, those elders between ages 55 and 59 are less likely to coreside than the 50-to-54 cohort, while those between 60 and 65 exhibit no significant difference from the 50-to-54 cohort. We thus conclude that between 2000 and 2011, coresidency to address the needs of adult children declined, and the nature of living arrangements in China grew more similar to those in the West, wherein coresidency increases with the age of the elderly, as they become less capable of independent living. ${ }^{9}$ We further explore this below, as we add variables that explicitly measure health and income.

While gender has little independent effect on coresidency, it has a strong positive effect of about 20 percentage points in both 2000 and 2011 in conjunction with widowhood. Widowhood, for women, appears to trigger the end of living independently from one's children. Widowhood, independent of gender has markedly different effects in 2000 and 2011. In the 2000 Census sample, all else equal, widowhood lowers the probability of living with one's adult children by approximately 7 percentage points. Combining this with the interacted gender effect suggests that in 2000 widows are about 13 percent more likely to live with their children. In 2011 the effects are much stronger. Widowhood by itself increases the probability of living with one's children by approximately 15 percentage points. The combined effect for female widows in the more recent data suggests their probability of living with adult children is 35 percentage points higher than for men who are not widowed. Again, this change is suggestive that family decision making is changing in rural Western China. Coresidency with one's adult children is no longer a given until the death of one's spouse brings about change. The data does not allow us to discern whether adult children are "called home" after the death of their parent or if the surviving spouse goes to live with his or her children.

The effects of provincial rural income per capita are similar across both samples. The higher provincial rural income, the less likely it is that rural elders coreside with their children. This result is consistent with the notion that income is inversely related to coresidency; those with the financial wherewithal to live independently are more likely to do so.

We are particularly interested in exploring ethnic differences in rural elders' living patterns. The probit regressions of Table 4 allow us to do so after controlling for potential differences in education levels, age distributions, probabilities of being widowed, and provincial income levels. It is interesting to note, given Confucian ideals of having many generations under one roof, that the Han are the least likely to coreside with adult children of the eleven ethnic groups in the analysis. The Tibetans are the most likely in 2000, followed by the Mongolians, Hui, Yao, Uyghur, and Miao. These ethnic coresidency differentials over the Han vary from 21.9 to 2.3 percentage points. The patterns revealed by CHES data are quite similar, although the smaller

\footnotetext{
${ }^{9}$ Zhang 2004.
} 
sample size leads to fewer ethnic groups with rates of coresidency that differ from the Han in terms of statistical significance. The differences between the two samples imply that the differentiation between particular ethnic groups and the Han is changing. The Tibetans diverged further from the Han (by 3 percentage points) over the 11 year period. The Uyghur and the Zhuang demonstrate extreme levels of increased divergence, from an 8 to 29 percent differential for the former and from no statistical difference to a 9 percent difference for the latter. Conversely it appears the Mongolians and the Hui grew more similar to the Han. These effects demonstrate that modernization is impacting various ethnic groups differently. The large negative interaction terms on widowhood and Tibetan and Uyghur ethnicities suggest that widowhood is not a defining event for either Tibetans and Uyghurs in terms of their of decisions about living with their adult children.

\section{Expanded Model of the Determinants of Coresidency, CHES Elders Sample}

\section{Alternative Model Specifications}

The CHES data allow us to include more factors in our model than were available in the Census data. Table 5, column 1 includes an expanded list of demographic variables including health status, income, housing and migration variables. Health status is indicated in two complementary ways: the first is an indicator of self-described disability that affects daily living; the second is an indicator of self-described difficulty (physical or psychological) experienced in the month prior to the survey. Both personal and family members' migration might affect elders' decision about coresiding with their children. We have included indicators of whether an elder ever migrated, whether an elder plans to migrate next year, and estimates of the current number of migrant workers from the elder's village reported by village officials. We expect that higher numbers of village migrants are positively correlated with the probability that elders' own children are out migrants, making them less likely to coreside with their children. ${ }^{10}$

\section{Table 5 Here}

To proxy for differences in income and wealth, we have included: household food expenditure per capita; an indicator variable if someone in the household receives a pension; the value and size of an elder's residence; ${ }^{11}$ and the average income in the elder's village. Meng and

\footnotetext{
${ }^{10}$ We do not know if an elder has a child in his/her same village at the time of the survey. The CHES survey provides information the number of children a woman has but does not provide this information for men. In a regression based only on women elders, we find that having more children is significantly positively related to the probability that female elders coreside with their children. The village migration effect is unchanged by the addition of the variable controlling for the number of children of women elders.

${ }^{11}$ Size could also be affected by living arrangements so we tried the model with and without house size and the results are unchanged.
} 
Luo suggested that, for their urban sample, pension was a good proxy for income. ${ }^{12}$ Pensions are much less common in rural than urban China, but nonetheless almost 30 percent of the elders in the CHES sample reported receiving some pension. Average village income may proxy for household wealth and may also affect the social norms of coresidency, via a neighborhood effect.

In column 2 we add ethnicity indicators and ethnicity interacted with widowhood. Then, in column 3 we further utilize the richness of the CHES data. We begin with the addition of individual attitudinal and behavioral indicators that measure the degree of assimilation between elderly minority individuals and the Han. The individually measured variables include responses to the survey statements "children should be allowed to marry outside their ethnic group," "it is easier to communicate with people of the same ethnic group as yourself" and "how many of your three best friends are members of the same ethnic group as yourself.” Additionally, we add a variable that indicates whether an individual lives in a single or mixed-ethnicity household, and one that indicates whether an individual can speak either Mandarin or the local Han dialect. All of these variables are binary, and coded such that a 1 represents a lack of cultural assimilation, and a 0 suggests greater similarity to the majority Han.

Furthermore we add county-level averages of the same three attitudinal variables. At the county-level we omit the language variable and include the proportion of the county that is of the same ethnicity as the elderly individual, and the county ethnicity concentration index - a measure of the ethnic diversity within the county. These latter two variables are calculated from published county-level data on ethnicity based on the 2000 Population Census of China and linked to the CHES data by county number. ${ }^{13}$ Although the degree of correlation between these last two variables is quite high at 0.7 , there are still substantial differences both within and between ethnic groups.

We expect these individual and county-level variables to be positively correlated with coresidency. At the individual level, reduced cultural assimilation suggests greater divergence from the Han across all spectrums, thus higher levels of coresidency. The county-level measurements are in place to capture the neighborhood effects that might influence the living arraignments of the elderly. If an individual is living in an area with a high level of assimilation, social norms may dictate behavior closer to Han behavior even if the individual elder professes more isolationist views.

\section{Demographic and Economic Determinants of Coresidency}

Table 5 demonstrates that the marginal effects on coresidency of the expanded economic and demographic factors are remarkably robust. By comparing the specification in column 1 and 2 we conclude that older age, losing a spouse, and, in addition, being a woman and losing one's husband affect Chinese rural elders in the same way, regardless of ethnicity. Even with the fuller

\footnotetext{
${ }^{12}$ Meng and Luo 2008.

${ }^{13}$ NBS and SEAC 2003.
} 
specification of Table 5 compared with Table 4 , it is clear that coresidency rates differ by age. Coresidency first declines with age from 50-to-54 to 55-to-59 as young adults leave home either because of migration or because they have built a new house nearby in the village. Lei $e t$ al. report that while coresidency has declined, adult children often live quite close to their parents. ${ }^{14}$ After age 60, coresidency begins to increase, first to the level of the age 50-to-54 group, and then more substantially. At ages 70-to-74 and 75 and above, rates of coresidency are 15 and 19 percentage points greater than those of the youngest elders. Becoming a widower or a widow are strong predictors of coresidency, raising rates by 19 and 38 (19 plus 19) percentage points respectively for the Han.

Elders whose disability affects their daily living are 6 percentage points more likely to coreside than others. This effect, however, becomes statistically insignificant with the addition of the individual and county-level assimilation measures. The other variable of well being, "faced difficulty (physical or psychological) in the last month," has a consistently negative marginal effect. It is probably better considered as an effect than a cause, that is, those who don't live with their children find tasks harder to accomplish.

Very few elders have migrated, and even fewer plan to migrate next year. These variables do not significantly affect coresidency. Living in a village with a high rate of migration does reduce the probability that elders live with their adult children. High rates of migration mean many elders are "holding down the fort", taking care of the farm and often their grandchildren. ${ }^{15}$

Finally, we consider the set of variables related to income and wealth. Meng and Luo found that receiving a pension reduced the probability of living with one's adult children for urban Chinese elders. ${ }^{16}$ We find the same for rural elders. This, along with the negative and consistently significant effect of food expenditure per capita and average per capita income in the village, is strong evidence that the privacy and independent living are valued by China's elders in ways that are similar for elders elsewhere. While the positive effect of house value may seem to contradict this supposition, this variable along with the statistically insignificant measure of house size are likely outcomes of the decision to coreside rather than causes. Those who live in three-generation households need bigger houses, which are often correlated with higher value. Running a specification that omitted house value and house size elicited no change in the marginal effects of any of the other variables.

\section{Results for Ethnic Indicators}

In Table 5 the Han majority remains the basis of comparison, thus reported marginal effects of ethnicity should be interpreted as differences from the Han. Having expanded the economic and demographic information in the model, we find that Tibetan, Uyghur, Zhunag and Salar elders have substantially higher probabilities of coresiding with their adult children than the Han.

\footnotetext{
${ }^{14}$ Lei et al. 2011.

${ }^{15}$ Connelly et al. 2014

${ }^{16}$ Meng and Luo 2008.
} 
While these effects persist in column 3 for the Tibetans and Uyghurs, they are statistically mitigated for the Zhuang and Salar with the inclusion of the individual and county-level assimilation/diversity variables.

Again, for Tibetans and Uyghurs, coresidence is not primarily a function of widowhood. Predicted coresidency rates for widows are higher than for non-widows for the Uygurs and the Tibetans, but the differentials are quite small. For the Han, widows and widowers are 37 and 19 percentage points, respectively, more likely to coreside. The Zhuang, Salar and Mongolians have higher differentials for widowhood (though these effects are measured imprecisely) than the Han. All of the 17 elderly widow and widower Salar included in the data live with their adult children.

\section{Assimilation Attitudes and Behavior Results}

Examining column 3 of Table 5, we see that at the individual level, the attitudinal variables hold no significance in the determination of coresidency. While we theorized that an isolationist outlooks would be consistent with higher rates of coresidency, individual attitudes may lag behind changing behavior brought on by changing economic circumstances. Turning to the more objective measure of the ability to communicate in Mandarin or the local Han dialect, we see that those incapable of doing so are significantly more likely to coreside. Language is good indicator of cultural assimilation, thus this result supports our hypothesis about the relationship between assimilation and coresidence.

Several of the county-level assimilation and diversity measures are also significant. Elders who live in counties with a higher share of people who have friends only from their own ethnic group are more likely to coreside than others. Similarly, elders in counties with lower rates of intermarriage among ethnic groups have a higher probability of coresiding. Contrasting, elders who live in counties with a high concentration index are less likely to coreside. Intuitively this seems to contradict the theory of assimilation which suggests more cultural integration means less traditional household arraignments. However, the concentration index takes on high values when there are fewer ethnic groups living in a particular county. Many counties have large Han populations, where only one other ethnic group has a significant presence. Thus, in a county that is 80 percent Han, and 20 percent Tujia, the concentration index will be high, but the Tujia are likely to be highly assimilated with the surrounding Han. In this sense concentration is not necessarily correlated with traditional living arraignments; that is, there is more than one way for a county to be heavily concentrated. The measures of intermarriage and integrated friendships more directly capture cultural synthesis in any given county.

\section{Further Robustness Tests}

While no consensus has emerged in the literature on living arrangements in China about the age at which to consider the question, Tables 4 and 5 show that age has a U-shaped relationship 
with coresidency. We hypothesize that by 2011 this dynamic stems from initial situations where adult children live with their parents in their early adult lives and during the period of migration. Then families separate with the adult children leaving their parents' home. ${ }^{17}$ Eventually, as parents age, coresidence may return with the parents moving in with their children either at the time of widowhood or just as a function of age and frailty. To test this relationship, we rerun the models of Table 5 limiting the sample to those 65 years of age or older (results available from the authors). None of our major conclusions change. The higher rates of coresidency among the Uyghurs and Tibetans persist. However, the differentials are substantially reduced for the older sample. The Mongolians, Miao and Salar also have rates of coresidency significantly higher than the Han, between 9 and 13 percentage points, when we focus solely on elders over age 65 .

\section{The Effect of Coresidency and Ethnicity on Happiness}

Earlier works by Chen and Short and Chyi and Mao have explored the role of elders' coresidency with their adult children on their subjective wellbeing and/or happiness. ${ }^{18}$ Chen and Short base their analysis on the richly detailed data of the Chinese Longitudinal Healthy Longevity Survey, but solely focus on elders age 80 and over. They treat coresidence as an exogenous determinant, such that coresidence will increase happiness, but happiness does not influence the likelihood of coresidence. They find that coresidence with either an adult child or a spouse is a strong and significant factor in predicting happiness. They explain their findings as the result of cultural expectations in China, where Confucian ideology prescribes coresidence as a function of filial piety. They conclude that such an effect may be absent or reversed in Western countries where coresidence may be viewed as a defeat, the end of one's independence.

Chyi and Mao note the recent rapid decline in the share of China's elderly living with their adult children. ${ }^{19}$ They argue that social structural reforms and economic development are changing values and expectations. Their analysis is based on the data of the 2005 Chinese General Social Survey and restricted to elders over age 60 with at least one surviving child. After modeling the potential codependence of happiness and coresidence and taking into account a set of economic and demographic variables, they find that elders' happiness is significantly reduced by coresidence with their own children. It must be noted however, that they find the effect of living with a grandchild mitigates any negative effect of living with an adult child.

Here we build on the work of the aforementioned authors to explore how coresidence with adult children affects the subjective happiness of Western China's rural elders, taking ethnicity into account. Senik addresses the question of whether happiness is due not only to objective circumstances, but also to the way that circumstances are perceived across cultures due to intrinsic dispositional factors. ${ }^{20}$ She refers to the intrinsic factors that persist over several

\footnotetext{
${ }^{17}$ Chen 2009.

${ }^{18}$ Chen and Short 2008; Chyi and Mao 2012.

${ }^{19}$ Chyi and Mao 2012.

${ }^{20}$ Senik 2011.
} 
generations as cultural components of happiness and suggests they are the mentality and attitudes that are picked up in infancy, education, and socialization. Using European data on migrants, Senik finds that country of origin has a significant effect on happiness, and that the happiness of migrants depends on the typical level of happiness of people in their home countries. Similarly, Krause explores cultural differences in the degree of unhappiness arising from a negative shock such as unemployment. ${ }^{21}$ She uses the institutional conformity and cultural diversity of Switzerland as the setting for her analysis. She finds clear evidence of cultural differences in the effects of an unemployment shock on happiness.

Table 6 provides descriptive statistics on the level of happiness by ethnicity in the CHES rural elders data. Column 1 reports the share of each ethnic group's elders who report themselves as "very happy" or "happy" after being asked to assess their overall life satisfaction. It reveals that rural Chinese elders (aged 50 or more) in Western China report levels of happiness that differ quite substantially by ethnicity. At the extreme ends of the distribution are the Hui, 57.5 percent of whom report being happy, and Miao and Tujia elders of whom only 37.3 percent consider themselves happy. Column 2 reports the relative happiness share of each of the minorities in comparison to the happiness share of the Han. Columns 3 and 4 respectively separate the sample into those who do and do not coreside with their adult children, and reveal the share each cohort who considers themselves happy. ${ }^{22}$ Only 6 of the 11 ethnic groups in our analysis have higher average happiness shares when coresiding with their children.

\section{Table 6 Here}

Table 7 contains the results of an econometric model that regresses the effects of coresidency and ethnic classification on the overall subjective happiness of the elderly while also controlling for economic and demographic factors. Because residency and happiness may be jointly determined we use the two-stage residual inclusion (2SRI) method of Terza, Basu, and Rathouz. ${ }^{23}$ Once again, we report the marginal effects of the explanatory variables.

\footnotetext{
${ }^{21}$ Krause 2011.

${ }^{22}$ Note that our definition of coresidence is with adult children while Chen and Short (2008) included coresidence with one's spouse. We focus on coresidence with children as it is much more of a choice and it is this aspect of coresiding that has been declining over time.

${ }^{23}$ Terza et al. 2008. The 2SRI method calls for the researcher to include both the actual values of the observed indicator variable (in our case coresidency) and the residuals calculated from the first stage model that predicts this potentially endogenous variable. We used our fullest model of coresidency, presented in column 3 of Table 5, to make predictions of elders' coresidency and to calculate the residuals. This specification includes a large number of variables not included in the happiness equation. They serve as identifiers of the model. The 2SRI method, assuming valid identifiers, provides consistent estimates of all the variables included in the second stage and is easy to interpret. The marginal effect of the observed indictor variable of interest (coresidency here) provides the estimated effect of the exogenous portion of the characteristic, while the marginal effect of the residuals shows the relationship between unobservable variables of the codetermined choices. Thus, in our context, the marginal effect of coresidency in the happiness equation provides us with the answer to what is the direct effect of coresidency on happiness, while the marginal effect on the coresidency residuals provides us with an estimate of the nature of the relationship between the factors that determine coresidency and the factors that determine happiness.
} 
Overall, we find that coresidency is a strongly positive determinant of elders' happiness: coresidency with adult children increases the probability of reporting happiness by 27.5 percentage points. We also find that the marginal effect of the residuals from the predicted values of coresidence is large, negative and statistically significant. This indicates that the same unobserved forces that drive the decision to coreside influence the happiness of the elderly in a detrimental manner. An example of an unobserved characteristic might be health status (beyond the simple disability status included). Poor health could be expected to simultaneously increase the probability of coresidency and reduce happiness.

Higher education increases happiness, an effect found in many other contexts and explicable via the correlation between educational attainment and standard of living. Similarly, those with greater financial means, as evidenced by higher household per capita food expenditures and/or higher house value, were more likely to be happy. Age does not influence happiness until an elder reaches 70, at which time the effect is negative. However, for the cohort of 75 and older the effect is insignificant, which may simply be a function of the data, or the effect of increased satisfaction with a long life. Unsurprisingly, those who report having some physical or psychological difficulties in the last month are significantly less likely to report overall happiness.

The considerable variation in happiness by ethnicity present in the descriptive data in Table 6 is partially confirmed by the analytical model in Table 7. When economic and demographic factors are held constant, happiness does differ in significant ways across the ethnic groups of our analysis. All else being equal, the Hui are 14 percentage points more likely to consider themselves happy than the Han, while Miao elders are 8.5 percentage points less likely to consider themselves happy. These differences are perhaps best attributed to the cultural factors Senik discusses. ${ }^{24}$ None of the other differences between the reported happiness of the other ethnic groups and the Han are statistically different from zero. Further research pertaining to differences in happiness by ethnicity among other age groups is necessary to confirm the cultural differences.

\section{Conclusion}

This article has explored the determinants of coresidency with one’s adult children among a population of rural Chinese aged 50 or older in seven Western provinces in 2011 and one consequence of coresidency, reported happiness. Coresidency with one's adult children traditionally has been considered the ideal living arrangement in Chinese society. While the ideal was not universal in 1982, the 73 percent of elders coresiding with their children was quite high.

\footnotetext{
${ }^{24}$ Senik 2011.
} 
Although the share declined to 60 percent in 2000, it remains high in international perspective. China is a multi-ethnic country in which the cultural premium placed on coresidency differs among ethnic groups. These different ethnic groups also face diverging socioeconomic conditions. Because the 2011 CHES data focuses on Chinese provinces with large ethnic minority populations it is a very useful source of information on the current state of decision making surrounding coresidency.

As China has moved into the ranks of aged societies, coresidency of elders with their adult children has become an increasingly important policy concern. Concern over whether there will be sufficient care for the elderly is growing as migration of younger adults from rural to urban areas increases and the elderly population grows. Left-behind elders may find themselves simultaneously devoid of adult children with whom they can coreside and shouldering added burdens of care of left-behind grandchildren and agricultural work. ${ }^{25}$

Our analysis first considered a parsimonious model of coresidency that allowed us to compare the 2011 rural CHES data with rural data drawn from the same counties from the 2000 Population Census. The results for both 2000 and 2011 demonstrate that socioeconomic variables matter in the determination of coresidency in China in ways that are very similar to their roles in other countries. However, changes between 2000 and 2011 in the effects of age and widowhood show that, in accordance with the notion proposed by Zhang, coresidency decisions among rural elders in the Western provinces are transitioning from child-centric to parentcentric. ${ }^{26}$ Finally the comparison has also revealed the large role cultural norms play in determining coresidency, as evidenced by the differences across ethnic groups.

Next, taking full advantage of the richness of the CHES data, we estimate models of coresidency that include key economic and demographic information not available in the Census data. Income has a persistent negative effect on coresidency, a result consistent with the findings of Meng and Luo in their analysis of coresidency in an urban Chinese context. ${ }^{27}$ Disability is always positively related to coresidency. Widowhood is an important determinant of coresidency, especially for women, except for Tibetans and Uyghurs. These groups have coresidency patterns that are high by comparison to the Han even controlling for all other factors, in which coresidency is largely independent of widowhood status.

The CHES data further allow us to compare coresidency across ethnicity in consideration of both individual and regional levels of assimilation versus isolation. Most of our individual measures of assimilation/isolation have no statistically significant effects on coresidency, but elders who do not speak either Mandarin or the local Han dialect have higher rates of coresidency with their adult children. Additionally, those who live in counties with low rates of intermarriage and intergroup friendships are also more likely to coreside.

Finally, we consider the effect of coresidency on a self-reported global happiness measure. In exploring the determinants of happiness, we find again that socioeconomic and demographic

\footnotetext{
${ }^{25}$ Connelly et al. 2014

${ }^{26}$ Zhang 2004.

${ }^{27}$ Meng and Luo 2008.
} 
conditions matter, as does ethnicity. Controlling all else, it seems that coresidency increases the happiness of the elderly by about 28 percent. Moreover, the unobserved characteristics that drive coresidency are highly detrimental to the happiness of the elderly. These effects only heighten the implications of the decline in coresidency, as they make clear that this trend is detrimental to the life satisfaction of the elderly.

We plan additional analyses of the CHES data to further explore the findings reported here. First, we plan to change the perspective of the analysis of coresidency to that of the adult children instead of the elders. This will allow us to explore the role that grandchildren play in the determination of coresidency. Similarly, we plan to consider ethnic differences in happiness as they relate to coresidency for the population of adult children. ${ }^{28}$ Our efforts to understand the relationships between elders and adult children would be enhanced by knowing whether the elders have adult children living in the same or close-by villages and whether the elders have non-coresident grandchildren. It is our hope that these questions will be included in the next round of CHES data collection planned for 2015.

\footnotetext{
${ }^{28}$ Knight and Li (2013) explore issues of ethnic differences in happiness more broadly.
} 


\section{References}

Cai, Fang, John Giles, Philip O’Keefe, and Dewen Wang. 2012. The Elderly and Old Age Support in Rural China: Challenges and Prospects. The World Bank: Washington, D.C. Chen, Feinian. 2009. "Family Division in China's Transitional Economy." Population Studies 63 (1), 53-69.

Chen, Feinian, and Susan E. Short. 2008. "Household Context and Subjective Well-Being Among the Oldest Old in China." Journal of Family Issues 29 (10), 1379-1403.

Cheng, Terence, Nattavudh Powdthavee, and Andrew Oswald. 2014. "Longitudinal Evidence for a Midlife Nadir in Human Well-being: Results from Four Data Sets.” IZA Discussion Paper No. 7942.

Chu, C. Y. Cyrus, Yu Xie, and Ruoh Rong Yu. 2011. "Coresidence With Elderly Parents: A Comparative Study of Southeast China and Taiwan." Journal of Marriage and Family 73 (1), 120-135.

Chyi , Hao, Shangyi Mao. 2012. "The Determinants of Happiness of China’s Elderly Population," Journal of Happiness Studies, Springer, vol. 13(1), pages 167-185, March. Connelly, Rachel, Margaret Maurer-Fazio and Dandan Zhang. 2014. "The Role of Coresidency with Adult Children in the Labor Force Participation Decisions of Older Men and Women in China.” IZA Discussion Paper No. 8068.

Cong, Zhen, and Merril Silverstein. 2011. "Intergenerational Exchange Between Parents and Migrant and Nonmigrant Sons in Rural China." Journal of Marriage and Family 73 (1), 93104.

Guo, Man, Iris Chi, and Merril Silverstein. 2012. "The Structure of Intergenerational Relations in Rural China: A Latent Class Analysis." Journal of Marriage and Family 74 (5), 1114-1128.

Knight, John and Li Shi, 2013.“Minorities in Rural China: Poorer But (Conditionally) Happier?” Paper presented at the CASS Forum on Development and Well-being Construction in Western Minority Areas of China, Beijing, November 22, 2013.

Krause, Annabelle. 2011. "Work to Live or Live to Work? Unemployment, Happiness, and Culture.” IZA Institute Discussion Paper No. 6101.

Lei, Xiaoyan, John Strauss, Meng Tian, and Yaohui Zhao. 2011. "Living Arrangements of the Elderly in China: Evidence from CHARLS." IZA Institute Discussion Paper No. 6249.

Li, Bin, and Sheying Chen. 2011. "Aging, Living Arrangements, and Housing in China." Ageing International 36 (4), 463-474.

Meng, Xin, and Chuliang Luo. 2008. "What Determines Living Arrangements of the Elderly in Urban China." In Bjorn Gustafsson, Shi Li and Terry Sicular (eds.), Inequality and Public Policy. Cambridge, MA: Cambridge University Press, 267-286.

NBS and SEAC. 2003. National Bureau of Statistic, P.R.C Department of Population, Social Science, and Technology Statistics and State Ethnic Affairs Commission, Department of Economic Development, The Tabulation on Nationalities of 2000 Population Census of China, Ethnic Publishing House: Beijing. 
Poston Jr, Dudley L., and Jing Shu. "The demographic and socioeconomic composition of China's ethnic minorities." Population and Development Review(1987): 703-722.

Senik, Claudia. 2011. "The French Unhappiness Puzzle: The Cultural Dimension of Happiness." IZA Institute Discussion Paper No. 6175.

Staiger, Douglas and James Stock. 1997. "Instrumental Variables Regression with Weak Instruments,” Econometrica 65(3), 557-586.

Terza, Joseph V., Anirban Basu, and Paul J. Rathouz. 2008. "Two-stage Residual Inclusion Estimation: Addressing Endogeneity in Health Econometric Modeling.” Journal of Health Economics 27, 531-543.

Wang, Feng. 2012. "Racing toward the Precipice," in China Economic Quarterly, 17-2

Zeng, Yi and Zhengdian Wang. 2004. "Family and Changes of Living Arrangements of the Elderly in China," Chinese Journal of Population Science. No. 5, October 1, pp.2-8.(in Chinese)

Zhan, Heying Jenny, and Rhonda J. V. Montgomery. 2003. "Gender And Elder Care in China: The Influence of Filial Piety and Structural Constraints." Gender \& Society 17 (2), 209-229.

Zhang, Qian Forrest. 2004. "Economic Transition and New Patterns of Parent-Adult Child Coresidence in Urban China." Journal of Marriage and Family 66 (5), 1231-1245. 


\begin{tabular}{|l|c|c|c|}
\hline \multicolumn{1}{|l|}{ Table 1: Percent of Rural Elders Living with Adult Children } \\
\hline & $\begin{array}{c}\text { All Rural } \\
\text { Elders in 2000 } \\
\text { Population } \\
\text { Census }\end{array}$ & $\begin{array}{c}\text { Rural Elders in } \\
\text { 2000 Population } \\
\text { Census Sample, } \\
\text { CHES Survey }\end{array}$ & $\begin{array}{c}\text { Rural Elders in } \\
2011 \text { CHES } \\
\text { Survey }\end{array}$ \\
& Sample & Counties Only & \\
\hline Han & $58.3 \%$ & $63.7 \%$ & $56.7 \%$ \\
Mongolian & $68.9 \%$ & $79.0 \%$ & $68.5 \%$ \\
Hui & $70.1 \%$ & $80.7 \%$ & $65.4 \%$ \\
Tibetan & $77.2 \%$ & $85.8 \%$ & $87.4 \%$ \\
Uygur & $66.1 \%$ & $69.9 \%$ & $86.5 \%$ \\
Miao & $67.7 \%$ & $67.3 \%$ & $66.3 \%$ \\
Zhuang & $70.0 \%$ & $66.1 \%$ & $73.8 \%$ \\
Dong & $66.3 \%$ & $66.3 \%$ & $65.6 \%$ \\
Yao & $70.0 \%$ & $73.0 \%$ & $70.9 \%$ \\
Tujia & $53.9 \%$ & $60.6 \%$ & $62.2 \%$ \\
Salar & $79.6 \%$ & $80.2 \%$ & $86.8 \%$ \\
Other Ethnic & $71.5 \%$ & $76.9 \%$ & $54.5 \%$ \\
\hline Total & $59.1 \%$ & $66.5 \%$ & $65.0 \%$ \\
\hline
\end{tabular}




\begin{tabular}{|l|c|c|}
\hline \multicolumn{1}{|l|}{ Table 2: Average Household Size } \\
\hline \multicolumn{1}{|c|}{$\begin{array}{c}\text { 2000 Population Census } \\
\text { Sample, CHES Survey } \\
\text { Counties Only }\end{array}$} & 2011 CHES Survey \\
Han & & \\
Mongolian & 3.8 & \\
Hui & 4.4 & 3.7 \\
Tibetan & 4.9 & 3.8 \\
Uygur & 5.4 & 4.4 \\
Miao & 4.6 & 4.7 \\
Zhuang & 4.0 & 4.8 \\
Dong & 3.7 & 4.0 \\
Yao & 4.0 & 3.8 \\
Tujia & 4.3 & 4.0 \\
Salar & 3.7 & 3.8 \\
Other & 5.3 & 4.0 \\
Ethnic & & 6.7 \\
\hline
\end{tabular}


Table 3: Share of Elder Households with at Least One Out Migrant, 2011 CHES

\begin{tabular}{|l|c|}
\hline & \% of households \\
Han & $40.4 \%$ \\
Mongolian & $35.7 \%$ \\
Hui & $45.2 \%$ \\
Tibetan & $28.5 \%$ \\
Uygur & $15.3 \%$ \\
Miao & $57.6 \%$ \\
Zhuang & $48.4 \%$ \\
Dong & $54.5 \%$ \\
Yao & $58.3 \%$ \\
Tujia & $49.2 \%$ \\
Salar & $59.3 \%$ \\
Other Ethnic & $68.0 \%$ \\
Minorities & \\
\hline
\end{tabular}




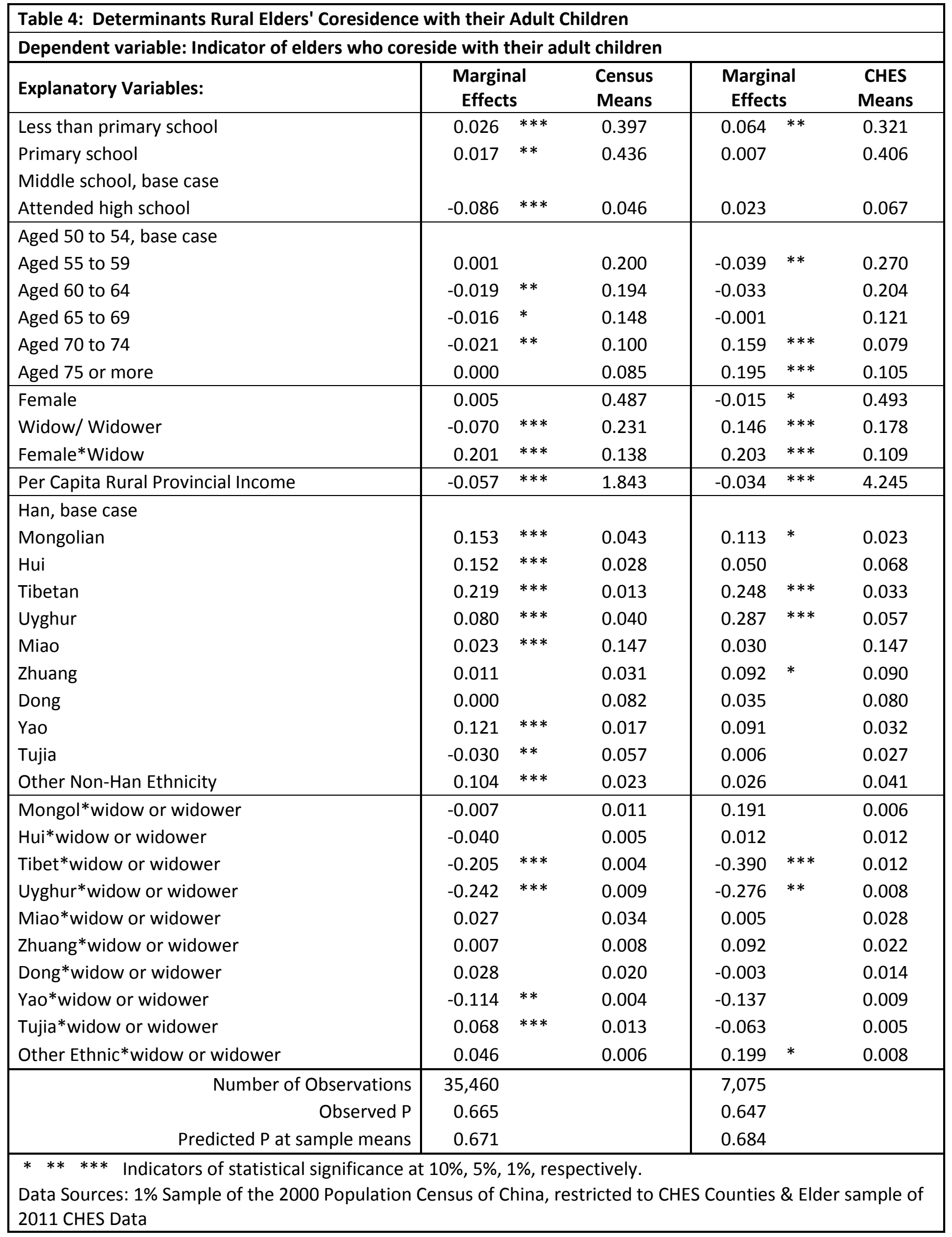




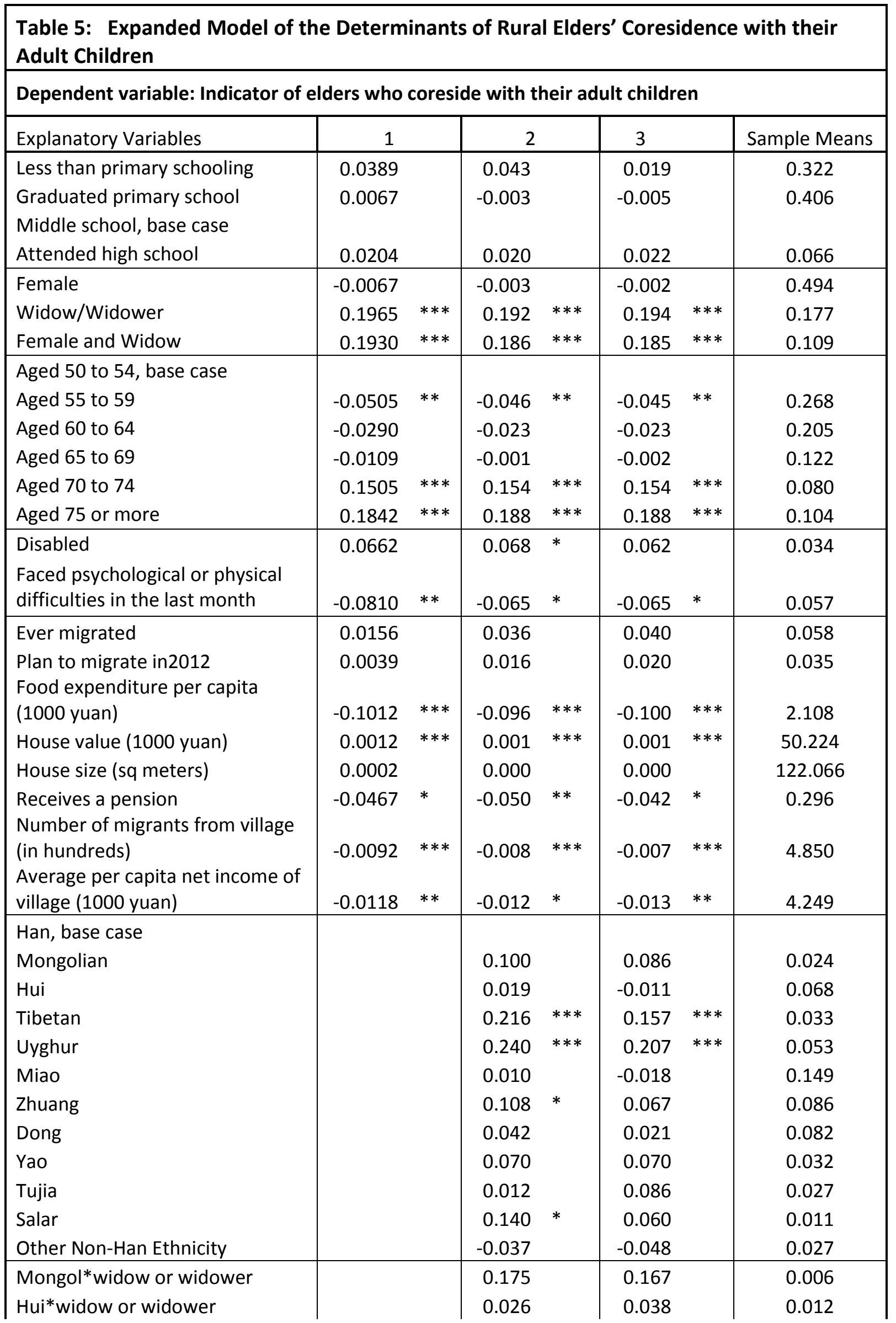




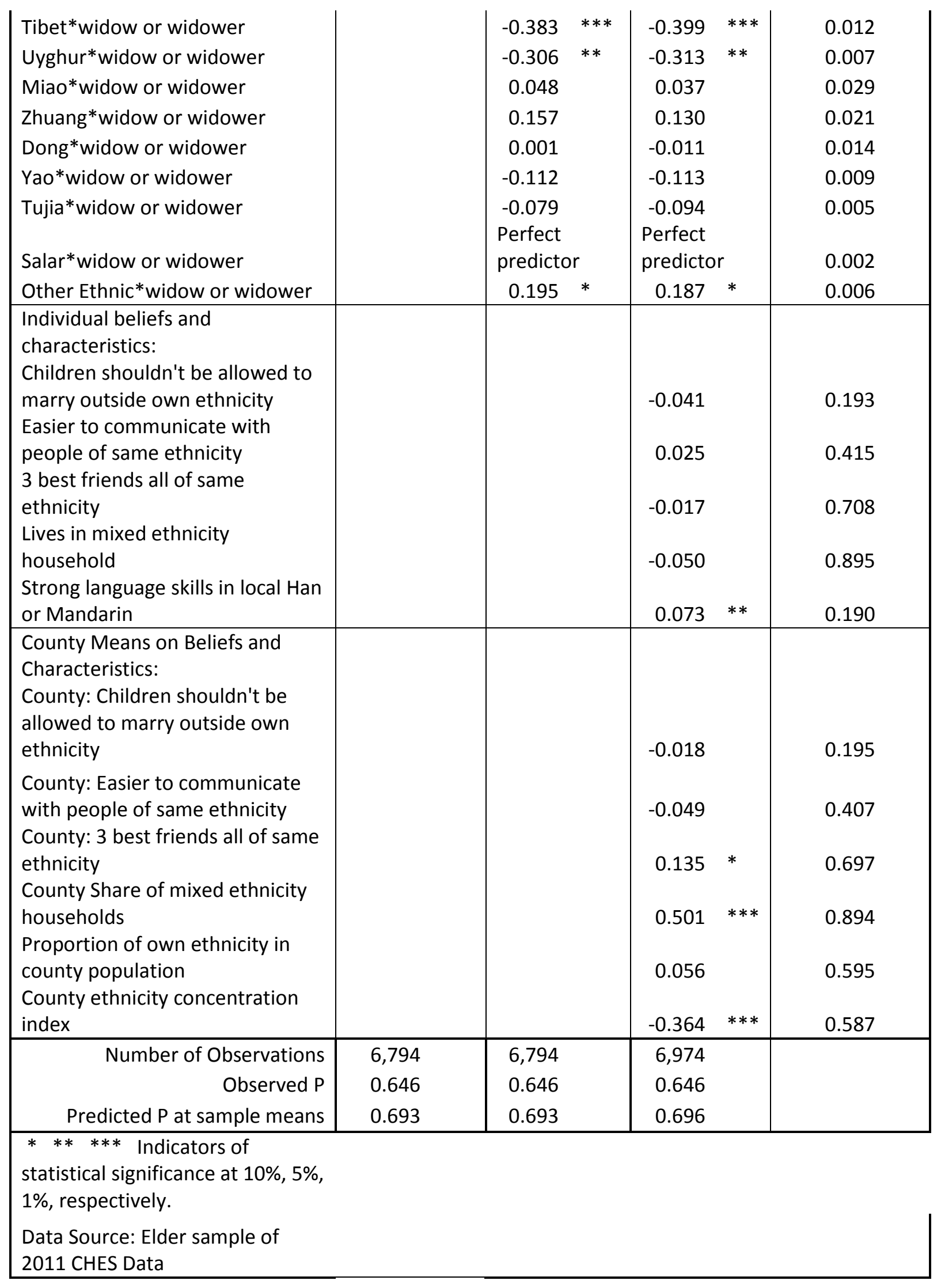




\begin{tabular}{|c|c|c|c|c|c|}
\hline \multirow[t]{2}{*}{ Ethnicity } & $\begin{array}{c}\text { Percent } \\
\text { Reporting } \\
\text { Being } \\
\text { Happy }\end{array}$ & $\begin{array}{c}\text { Ratio of } \\
\text { Shares } \\
\text { Reporting } \\
\text { Happiness of } \\
\text { Ethnic } \\
\text { Minorities } \\
\text { Relative to } \\
\text { Han }\end{array}$ & $\begin{array}{c}\text { \% Reporting } \\
\text { Happiness if } \\
\text { Coresiding } \\
\text { with Adult } \\
\text { Children }\end{array}$ & $\begin{array}{c}\text { \% Reporting } \\
\text { Happiness if } \\
\text { not } \\
\text { Coresding } \\
\text { with Adult } \\
\text { Children }\end{array}$ & $\begin{array}{c}\text { Difference in } \\
\% \text { Reporting } \\
\text { Happiness of } \\
\text { Coresident } \\
\text { and Non- } \\
\text { Coresident } \\
\text { Elders }\end{array}$ \\
\hline & 1 & 2 & 3 & 4 & 5 \\
\hline Han & $45.9 \%$ & 1.00 & $47.91 \%$ & $43.4 \%$ & $4.5 \%$ \\
\hline Mongolian & $55.4 \%$ & 1.21 & $53.04 \%$ & $60.4 \%$ & $-7.3 \%$ \\
\hline Hui & $57.5 \%$ & 1.25 & $54.78 \%$ & $62.7 \%$ & $-7.9 \%$ \\
\hline Tibetan & $53.7 \%$ & 1.17 & $53.52 \%$ & $54.8 \%$ & $-1.3 \%$ \\
\hline Uygur & $49.3 \%$ & 1.07 & $49.00 \%$ & $50.9 \%$ & $-1.9 \%$ \\
\hline Miao & $37.3 \%$ & 0.81 & $39.40 \%$ & $33.1 \%$ & $6.3 \%$ \\
\hline Zhuang & $41.7 \%$ & 0.91 & $43.25 \%$ & $37.5 \%$ & $5.7 \%$ \\
\hline Dong & $38.3 \%$ & 0.83 & $37.60 \%$ & $39.6 \%$ & $-2.0 \%$ \\
\hline Yao & $40.5 \%$ & 0.88 & $41.14 \%$ & $38.9 \%$ & $2.3 \%$ \\
\hline Tujia & $37.3 \%$ & 0.81 & $38.33 \%$ & $35.6 \%$ & $2.7 \%$ \\
\hline Salar & $50.5 \%$ & 1.10 & $50.63 \%$ & $50.0 \%$ & $0.6 \%$ \\
\hline Other & $39.5 \%$ & 0.86 & $33.94 \%$ & $46.2 \%$ & $-12.2 \%$ \\
\hline Total & $44.87 \%$ & $\sim$ & $45.76 \%$ & $43.23 \%$ & $2.53 \%$ \\
\hline
\end{tabular}




\begin{tabular}{|c|c|c|c|}
\hline \multicolumn{4}{|c|}{$\begin{array}{l}\text { Dependent variable: an indicator that counts elders as happy if they responded "very happy" or } \\
\text { "happy" to the question, "Taking account of all aspects of life, do you feel happy?" }\end{array}$} \\
\hline $\begin{array}{l}\text { Explanatory Variables: } \\
\text { Lives with adult children }\end{array}$ & \multicolumn{2}{|c|}{ Marginal Effects } & \multirow{2}{*}{$\frac{\text { Sample Means }}{0.646}$} \\
\hline Lives with adult children & 0.275 & $* *$ & \\
\hline Residuals on prediction of living with adult children & -0.259 & $* *$ & 0.000 \\
\hline Less than primary schooling & 0.031 & & 0.322 \\
\hline Graduated primary school & 0.020 & & 0.406 \\
\hline Middle school, base case & & & 0.206 \\
\hline Attended high school & 0.108 & $* * *$ & 0.066 \\
\hline Female & 0.000 & & 0.494 \\
\hline Widow/Widower & -0.059 & & 0.177 \\
\hline Female and Widow & -0.016 & & 0.109 \\
\hline Aged $50-54$, base case & & & 0.221 \\
\hline Aged 55 to 59 & 0.023 & & 0.268 \\
\hline Aged 60 to 64 & -0.014 & & 0.205 \\
\hline Aged 65 to 69 & 0.027 & & 0.122 \\
\hline Aged 70 to 74 & -0.068 & $*$ & 0.080 \\
\hline Aged 75 or more & -0.053 & & 0.104 \\
\hline Disabled & -0.068 & & 0.034 \\
\hline Faced psychological or physical difficulties in the last month & -0.102 & $* * *$ & 0.057 \\
\hline Ever migrated & -0.016 & & 0.058 \\
\hline Plan to migrate in 2012 & 0.004 & & 0.035 \\
\hline Food expenditure per capita (1000 yuan) & 0.039 & $* * *$ & 2.108 \\
\hline House value (1000 yuan) & 0.001 & $* * *$ & 50.224 \\
\hline House size (square meters) & 0.000 & & 122.066 \\
\hline Receives a pension & 0.013 & & 0.296 \\
\hline Han, base case & & & 0.409 \\
\hline Mongolian & 0.069 & & 0.024 \\
\hline Hui & 0.140 & $* * *$ & 0.068 \\
\hline Tibetan & 0.023 & & 0.033 \\
\hline Uygur & -0.052 & & 0.053 \\
\hline Miao & -0.086 & $* *$ & 0.149 \\
\hline Zhuang & -0.060 & & 0.086 \\
\hline Dong & -0.069 & & 0.082 \\
\hline Yao & -0.126 & & 0.032 \\
\hline Tujia & -0.106 & & 0.027 \\
\hline Salar & -0.012 & & 0.011 \\
\hline Other Ethnic Minority & -0.071 & & 0.027 \\
\hline Number of Observations & 6,974 & & \\
\hline Observed P & 0.446 & & \\
\hline
\end{tabular}




\begin{tabular}{|c|c|c|}
\multicolumn{4}{|c|}{ Predicted P at sample means 0.445} \\
\hline$* \quad * * \quad * * *$ & Indicators of statistical significance at $10 \%, 5 \%, 1 \%$, respectively. \\
Data Source: Elder sample of 2011 CHES Data
\end{tabular}

